\title{
Treatment of Liquefiable Soils by the Ballasted Column Technique: Case of Martil River Bridge in the North of Morocco
}

\author{
Youness Tlidi", Lahcen Bahi, Latifa Ouadif, Anas Bahi \\ 3GIE Laboratory, Mohammadia Engineering School, Mohammed V University, Rabat, Morocco
}

Received November 15, 2021; Revised December 31, 2021; Accepted February 8, 2022

\section{Cite This Paper in the following Citation Styles}

(a): [1] Youness Tlidi, Lahcen Bahi, Latifa Ouadif, Anas Bahi, "Treatment of Liquefiable Soils by the Ballasted Column Technique: Case of Martil River Bridge in the North of Morocco," Civil Engineering and Architecture, Vol. 10, No. 2, pp. 659-668, 2022. DOI: 10.13189/cea.2022.100221.

(b): Youness Tlidi, Lahcen Bahi, Latifa Ouadif, Anas Bahi (2022). Treatment of Liquefiable Soils by the Ballasted Column Technique: Case of Martil River Bridge in the North of Morocco. Civil Engineering and Architecture, 10(2), 659-668. DOI: 10.13189/cea.2022.100221.

Copyright $(2022$ by authors, all rights reserved. Authors agree that this article remains permanently open access under the terms of the Creative Commons Attribution License 4.0 International License

\begin{abstract}
The seismic activity in northern Morocco is largely due to an intense tectonic activity Plio-Quaternary and current generated by the approach of the two lithospheric plates Africa-Eurasia. Certainly, the liquefaction of soils is a phenomenon that presents a potential risk and a major challenge for the construction of foundations of engineering structures. The objective of this work is the realization of test plates to decide on adequate treatment in a soil liquefiable. For our case during the construction of a double bridge on a liquefiable soil and in a seismic zone, we were confronted with two technical problems, on the one hand the choice of the method of treatment of the soil in place and on the other hand the verification of this improvement by the results of the CPT tests (Cone Penetration Test) carried out before and after the densification of the soil. Many types of liquefaction remediation methods have been developed. However, for our case, the results indicate the effectiveness of the vibrocompaction method in improving the in-place soil compared to the dry method in eliminating the risk of soil liquefaction. It should be noted that the wet columns were lowered to $22 \mathrm{~m} / \mathrm{TN}$, and the dry columns were stopped at varying depths between 2 and $14 \mathrm{~m} / \mathrm{TN}$, and the results of the CPT (Cone Penetration Test) confirm the effectiveness of vibrocompaction and that the bridge foundations are protected against the phenomenon of soil liquefaction.
\end{abstract}

Keywords Ballasted Column, Liquefaction
Phenomena, Dry-Laid Columns CPT, Vibrocompaction

\section{Note Preface to This Article}

This work has been initiated by a rather particular experience following the construction and duplication of a bridge river Martil river located in the city of Tetouan in northern Morocco [1], to take into account the liquefaction of soils which is a serious problem capable of causing damage often irreparable, both to existing structures and to new constructions. The objective is articulated in four main themes:

- Techniques of implementation,

- Soil behavior,

- Methods of justification,

- processing verification

\section{Introduction}

Liquefaction is a phenomenon, in which the shear strength of a soil is reduced by the shaking of an earthquake [2] or other rapid loading. Soil liquefaction is a major hazard for structures built or founded on sandy, saturated soils. 
The proposed study falls into this category. It is applied to the foundation of a double structure with reinforced concrete beams. In water-saturated fin soils, the presence of water [11] causes a pore pressure on the soil particles, which decreases the effective stresses in the soil and thus decreases its shear strength which, in the ultimate state, may become negligible.

Before an earthquake, the water pressure is relatively low. However, the shaking of an earthquake can cause a considerable increase in pore water pressure to the point where soil particles can easily move relative to each other [13].

In addition, the ballasted column plays a draining role thanks to the high permeability of the gravel combined with an increase in the hydraulic gradient resulting from the phenomenon of dilatation that appears in the ballasted columns during a dynamic solicitation [5].

\section{Site Presentation}

As shown in Figure 1, the site is located in the north of Morocco at $3 \mathrm{~km}$ from the city of Tetouan towards the city of Chefchaouen. The project consists of the construction of a bridge over Martil river at PK 52+400 at the level of the expressway connecting the city of Tetouan and Chefchaouen in the north of Morocco

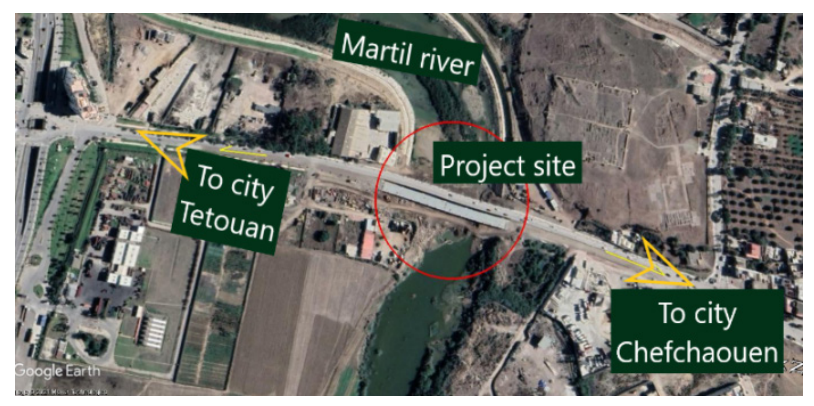

Figure 1. Location of the site project

Moreover, it is to be specified that the foundation of the structure must be protected against the phenomenon of soil liquefaction by using the technique of ballasted columns according to the plan layout illustrated in Figure 2.

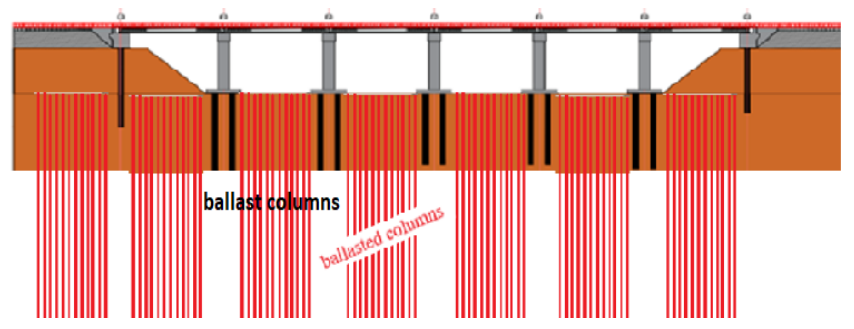

Figure 2. Plan layout of the ballasted columns

\section{Context and Geotechnical Reconnaissance}

The geotechnical campaign consisted in the execution of six core drillings descended between 43 and $60 \mathrm{~m}$ depth, with the calculation of the different pressures reported in Figure 3.

The main results of the drillings carried out and representing the soil lithology are summarized in Table 1 below:

Table 1. Geographical coordinates and depth of drillings

\begin{tabular}{ccccc}
\hline \multirow{2}{*}{ Drilling } & $\begin{array}{c}\text { Type of } \\
\text { drilling }\end{array}$ & \multicolumn{2}{c}{ Geographical coordinates } & Depth \\
\cline { 3 - 4 } & & $\mathbf{X}$ & $\mathbf{Y}$ & \\
\hline SPT01 & Destructive & 498732,18 & 551107,47 & 30 \\
\hline SPT02 & Destructive & 498741,49 & 551052,25 & 30 \\
\hline SPT03 & Destructive & 498717,57 & 551038,62 & 30 \\
\hline SPT05 & Destructive & 498710,40 & 551011,43 & 33 \\
\hline SPT06 & Destructive & 498734,69 & 550982,28 & 25 \\
\hline SPT07 & Destructive & 498722,05 & 550958,56 & 27 \\
\hline
\end{tabular}

It should be noted that the lithology of the soil in place is as shown in Figure 3. 


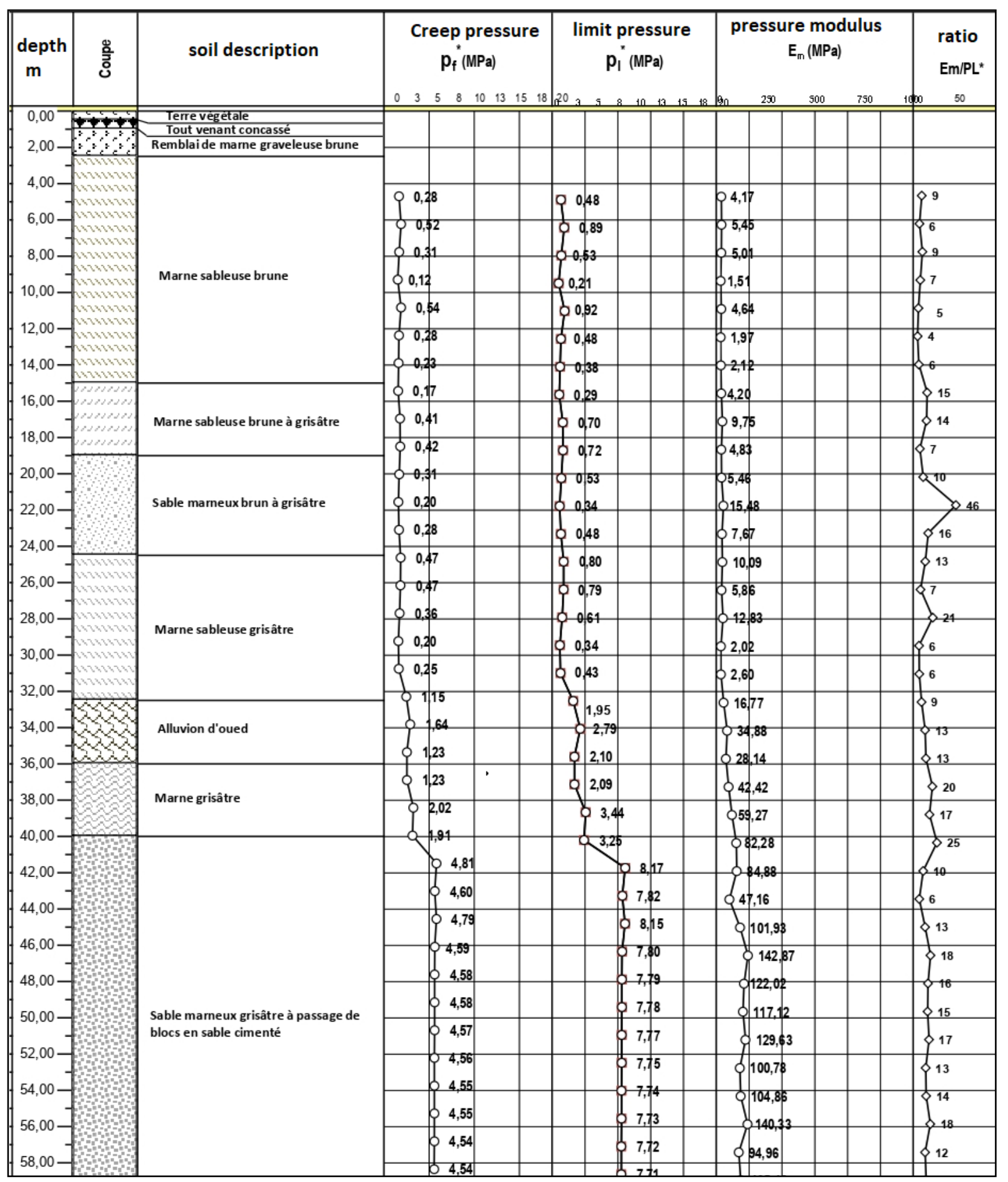

Figure 3. Lithological section

From a stratigraphic point of view, the lithology of the soil is constituted by the succession of formations as shown in Figure 3 and detailed as follows:

- Alluvial soil, $0.3 \mathrm{~m}$ thick

- Brown gravelly marl, with a thickness of $1.8 \mathrm{~m}$.

- Brown sandy marl, with a thickness of $12.5 \mathrm{~m}$.

- Brown to greyish sandy marl, $4 \mathrm{~m}$ thick.

- Brown to greyish marly sand, $5.5 \mathrm{~m}$ thick.

- Greyish sandy marl, with a thickness of $8 \mathrm{~m}$

- Wadi alluvium, $3.5 \mathrm{~m}$ thick

- Above and down to the bottom of the borehole, greyish marly sands with cemented sand passage are encountered 
Table 2. The results of the SPT tests

\begin{tabular}{|c|c|c|c|c|c|c|c|c|}
\hline \multirow[b]{2}{*}{ Drilling } & \multirow[b]{2}{*}{$\begin{array}{c}\text { Depth } \\
\text { (m) }\end{array}$} & \multirow[b]{2}{*}{ Lithological nature } & \multicolumn{3}{|c|}{ Granulometric analysis } & \multicolumn{2}{|c|}{ Atterberg limits } & \multirow[b]{2}{*}{ W $(\%)$} \\
\hline & & & $\begin{array}{c}< \\
0,08 \\
\mathrm{~mm} \\
\end{array}$ & $\begin{array}{l}>2 \\
\mathrm{~mm}\end{array}$ & $>50 \mathrm{~mm}$ & WL (\%) & IP $(\%)$ & \\
\hline \multirow[t]{4}{*}{ SPT01 } & $16,00 / 16,50$ & Brown sandy marl & 81,7 & 0,6 & 0,0 & - & - & 20,4 \\
\hline & $11,50 / 12,00$ & Brown to greyish sandy marl & 87,5 & 0,7 & 0,0 & - & - & 18,8 \\
\hline & $14,00 / 14,50$ & Brown to greyish marly sand & 36,2 & 1,3 & 0,0 & - & - & 19,2 \\
\hline & $15,50 / 16,00$ & Brown to greyish sandy marl & 35,3 & 18,4 & 0,0 & - & - & 20,2 \\
\hline
\end{tabular}

The results of the SPT tests are represented in Table 2. Also, according to the prescriptions of the French association of seismic engineering, the soil up to $20 \mathrm{~m}$ depth is a priori vulnerable to the phenomenon of liquefaction, and it presents the following characteristics:

- The degree of saturation of around $100 \%$

- Average uniformity coefficient value $\mathrm{Cu}$

$$
\begin{gathered}
\left(\mathrm{D}_{60} / \mathrm{D}_{10}\right)<15 \\
50_{\mu \mathrm{m}}<\mathrm{D}_{50}<1,5 \mathrm{~mm}
\end{gathered}
$$

\section{Treatment of the Foundation by the Vibrocompaction Technique}

The flexible inclusions, in the broadest sense of the term, were developed to allow the improvement of soils with poor geotechnical qualities. The incorporation and compaction of a material having selected geotechnical characteristics to the soil in place lead to a reinforcement of the latter. The various methods of improvement respond to technical constraints related to the geotechnical characteristics of the soil in place [4].

The objectives expected from a soil improvement by flexible inclusions can be summarized as follows:

- The increase of the bearing capacity of the soil

- The increase of its shear resistance;

- The reduction of settlements;

In addition, in areas potentially subject to earthquakes, an attenuation of the liquefaction potential of saturated loose sands is induced by the installation of a network of columns. Indeed, taking into account the draining power of the material constituting the columns, the interstitial overpressures created during an earthquake can be dissipated with more or less effectiveness according to the mesh of the columns.

Soil improvement by flexible inclusions must take into account many parameters involved in the design, the implementation, the mechanical behavior of both of the inclusions but also of the structure. Indeed, one cannot conceive a soil improvement without being concerned about the loading mode which will be really set up.

For the improvement of this soil, we have opted to carry out two test beds with two methods of execution, namely the dry method and the wet method; two conclusions have been highlighted concerning these two test beds namely:

- During the realization of the columns by dry way, we noted difficulties to reach the required depth with a pressure exceeding the 200 bars whose depth reaches between 2 to $14 \mathrm{~m} / \mathrm{TN}$. and as soon as the vibrator encounters a stubborn layer preventing its descent to reach the required depth of 22 meters.

- On the other hand, the columns executed by wet method went down to 22 meters required by the contractual specifications. However, the execution did not give rise to surface slumps; the incorporated volume of ballast is greater than 1.4 of the theoretical volume [5].

- Also, these flexible inclusions are not independent elements of the soil to be improved.

- The soil-column interaction [6] is one of the most delicate aspects to treat and cannot be summarized by a simple calculation of piles or rigid inclusion [7]. Their mode of operation, of behavior, is established in close collaboration with the surrounding soil which cannot be ignored, even if the geotechnical characteristics of the soil are mediocre, even bad.

\section{Operating Mode}

Following the various expertise carried out [8], the solution of treatment by the dry way was discarded and the solution retained is the execution of the ballasted columns [3] via the wet way [9], according to the mesh specified in Figure 4 and the following procedure:

- Drilling: Before the operation, it is necessary to ensure the verticality illustrated in Figure 5. The tool, whose power and characteristics are variable according to the terrain, is ground, is driven to the final depth to be reached. Its descent is made thanks to the combined effect of its weight, the vibration and the jetting water as shown in Figure 6. The water flow is then decreased.

- Compacting: the vibro-compaction is then carried out by successive passes from bottom to top. The compacted volume is a cylinder with a diameter of 
up to $5 \mathrm{~m}$. The progressive increase of the intensity consumed by the vibrator allows the growth of the soil compactness.

- Material input [10]: Around the vibrator appears a cone of subsidence that is progressively filled in either by adding materials or by stripping

- progressively the materials of the site according to the initial state, one can reach a quantity of $10 \%$ of added materials compared to the treated illustrated in Figure 7

- Finishing: After treatment, the platform is adjusted and recompacted with a vibrating roller.

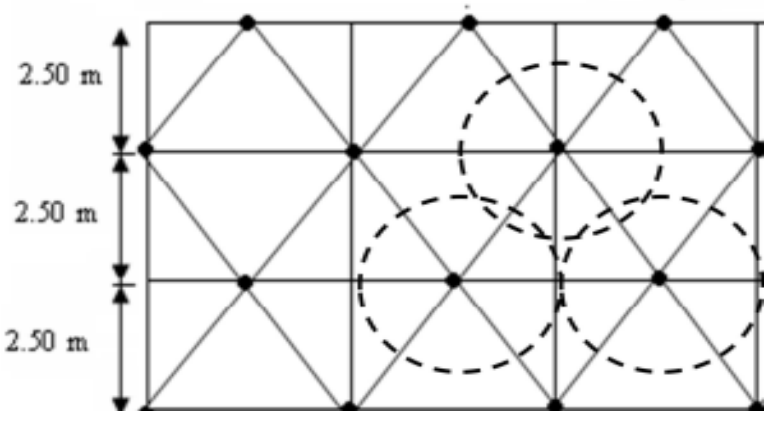

Figure 4. Triangular mesh treated

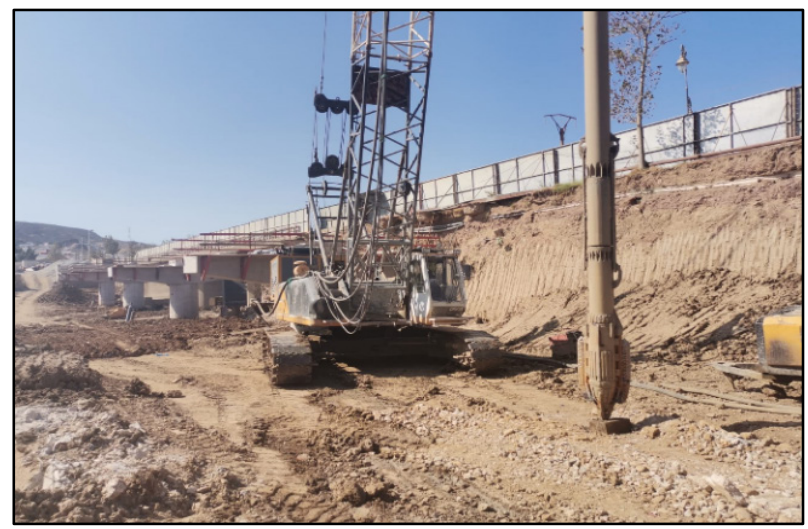

Figure 5. Verticality of the column

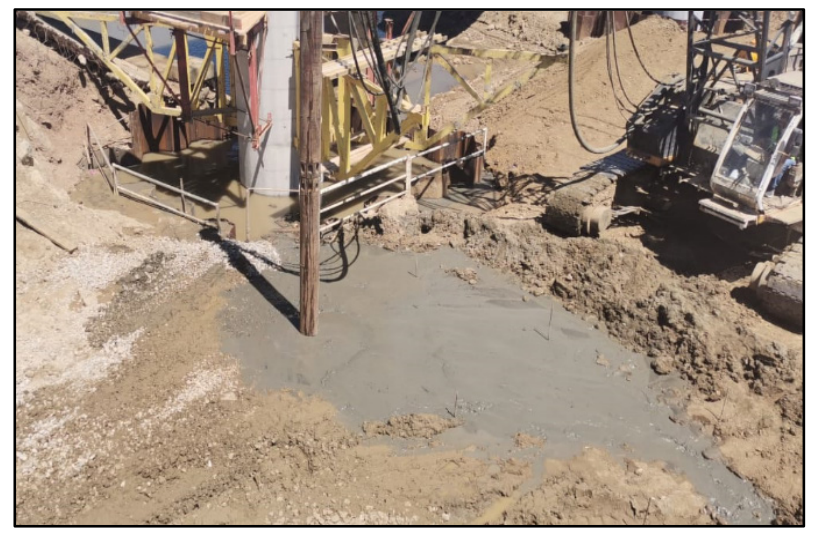

Figure 6. Execution of the ballasted column

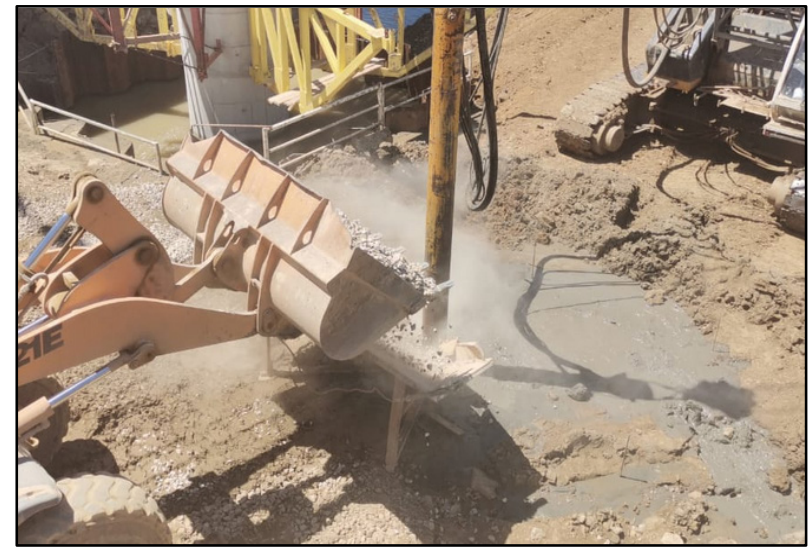

Figure 7. Incorporation of ballasts

The implementation of ballasted columns by wet method, also called vibro-replacement, consists in:

- drilling by self-drilling and water jetting to the designated depth,

- raising the vibrator, sometimes with successive ramming, and letting the ballast fall by gravity into the previous drilling,

- compact the ballast in successive passes until the column is finished.

The improvement of the mechanical properties of soils depends essentially on:

- the nature of the soil to be treated with ballasted columns;

- the mesh size adopted;

- the capacity of the vibrator to "densify" the fine casing soil

\section{Risk Assessment of Soil Liquefaction}

The following Table 3 gives the depths where soil liquefaction occurs.

The analysis of the data of Table 3 highlights a potential risk of soil liquefaction [11] up to $20 \mathrm{~m}$ deep after reprofiling.

The optimal solution consists of incorporating ballasted columns with a depth of $22 \mathrm{~m}$ and an inter-axis distance of $2.5 \mathrm{~m}$.

It should be remembered that the treatment of soils with ballasted columns allows:

- Accelerate drainage [11]because the columns act as drains to dissipate the interstitial overpressures

- To attenuate the impact of the seismic action, because the shear stress induced by the

- induced by the earthquake is distributed between the soil and the ballasted column, and this in

- proportion to the load transfer and the relative soil/column stiffnesses;

- To reduce the risk of soil liquefaction by the draining effect of the ballast. 
Table 3. Experimentation of the liquefaction depth

\begin{tabular}{|c|c|c|c|c|c|c|c|c|c|c|c|c|c|}
\hline & $\mathbf{Z}$ & $\begin{array}{c}\gamma_{\text {sol }} \\
\mathbf{K N} / \\
m^{3} \\
\end{array}$ & $\begin{array}{c}P_{l} \\
\mathbf{M P a}\end{array}$ & $\begin{array}{c}\mathbf{N} \\
\text { SPT }\end{array}$ & $\begin{array}{c}\sigma_{v} \\
\mathbf{K P a}\end{array}$ & $\sigma_{v}^{\prime}$ & $\mathrm{CN}$ & $\begin{array}{c}\text { Thin } \\
\%\end{array}$ & $N_{60}$ & CSR & $\begin{array}{c}\text { CRR } \\
7,5\end{array}$ & $\begin{array}{c}\text { CRR } \\
6\end{array}$ & Liquefaction \\
\hline SCP1 & 8,55 & 20 & 0,24 & 4,87 & 171 & 94 & 1 & 38 & 4,3 & 0,352 & 0,12 & 0,264 & Yes \\
\hline \multirow{4}{*}{$\mathrm{SCP} 2$} & 13,40 & 20 & 0,13 & 2,67 & 268 & 147,4 & 0,81 & 29 & 1,9 & 0,322 & 0,1 & 0,22 & Yes \\
\hline & 15,9 & 20 & 0,31 & 6,13 & 318 & 175 & 0,75 & 35 & 4,1 & 0,300 & 0,12 & 0,26 & Yes \\
\hline & 16,9 & 20 & 0,55 & 11 & 338 & 186 & 0,72 & 35 & 7 & 0,300 & 0,16 & 0,35 & Yes \\
\hline & 20 & 20 & 0,22 & 4,4 & 400 & 220 & 0,67 & 33 & 2,65 & 0,280 & 0,1 & 0,22 & Yes \\
\hline \multirow{4}{*}{ SP5 } & 2,2 & 20 & 0,35 & 6,9 & 44 & 24,2 & 2 & 31 & 12,4 & 0,39 & 0,21 & 0,46 & Yes \\
\hline & 3,5 & 20 & 0,23 & 4,5 & 70 & 38,5 & 1,6 & 31 & 6,4 & 0,38 & 0,19 & 0,42 & Yes \\
\hline & 4,2 & 20 & 0,16 & 3,2 & 84 & 46,2 & 1,47 & 14,8 & 4,2 & 0,37 & 0,1 & 0,22 & Yes \\
\hline & 5,2 & 20 & 0,21 & 4 & 104 & 57,2 & 1,32 & 14,8 & 4,7 & 0,37 & 0,1 & 0,22 & Yes \\
\hline
\end{tabular}

To date, there are no sufficiently developed and well-known methods [12] to study the behavior of ballasted columns in seismic zones. However, despite the limited development and research results in this field, some authors have developed approaches to study the seismic behavior of soils treated with ballasted columns and to evaluate the risk of liquefaction.

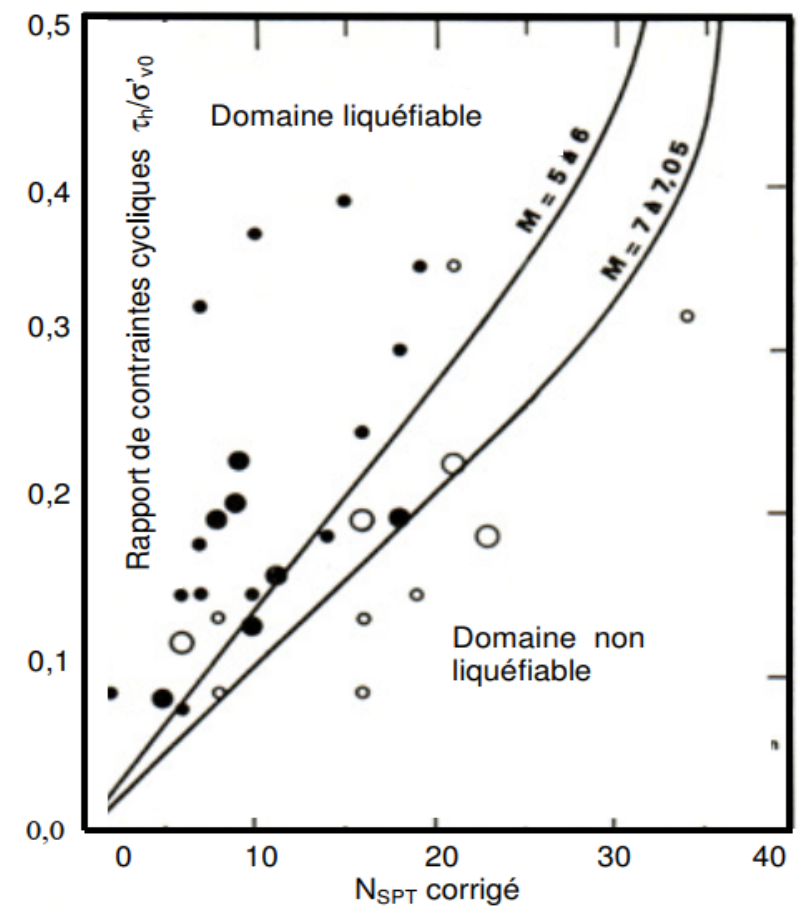

Figure 8. Liquefaction: correlations between the ratio of cyclic stresses

In seismic areas, Priebe proposes an approach based on correlations similar to those of Seed show Figure 8 [13], which allows the ratio of the cyclic shear stress generated by the earthquake $\tau$ h to the effective vertical stress $\sigma_{v 0}^{\prime}$ prevailing in the soil to be expressed as follows:

$$
\frac{\tau_{\mathrm{h}}}{\sigma_{\mathrm{v} 0}^{\prime}}=0,1(\mathrm{M}-1) \cdot \frac{\mathrm{a}_{\max }}{\mathrm{g}} \cdot \frac{\sigma_{\mathrm{v} 0}}{\sigma_{\mathrm{v} 0}^{\prime}} \cdot \mathrm{r}_{\mathrm{d}}
$$

Where:

$M$ is the earthquake magnitude,

$g$ is the acceleration of gravity,

$\sigma \mathrm{v}_{0}$ is the total vertical stress in the ground,

$r_{d}$ is a depth-dependent reducing coefficient $\mathrm{Z}$.

To introduce the influence of columns on the earthquake-induced shear stress [14], Priebe [13] makes a correction to the cyclic stress ratio through the enhancement factor $n_{0}$, which is:

$$
\left(\frac{\tau_{\mathrm{h}}}{\sigma^{\prime} \mathrm{v} 0}\right)_{\text {corrigé }}=\frac{1}{\mathrm{n}_{0}}\left[0,1(\mathrm{M}-1) \cdot \frac{\mathrm{a}_{\max }}{\mathrm{g}} \frac{\sigma_{\mathrm{v} 0}}{\sigma_{\mathrm{v0}}^{\prime}} \cdot \mathrm{r}_{\mathrm{d}}\right]
$$

The substitution factor (in the case of wet-laid columns) or the incorporation rate (in the case of wet-laid columns) is (in the case of wet-laid columns) or the incorporation rate (in the case of dry-laid columns) is the ratio a of the treated area Ac (cross-sectional area of the column) to the total area $A$ of the area of influence of the column (unit cell principle) i.e.:

$$
\begin{gathered}
\mathrm{a}=\frac{\mathrm{A}_{\mathrm{c}}}{\mathrm{A}} \\
\mathrm{n}_{0}=1+\mathrm{a}\left[\frac{1}{\mathrm{~K}_{\mathrm{ac}}(1-\mathrm{a})}-1\right] \\
\mathrm{K}_{\mathrm{ac}}=\tan ^{2}\left(\frac{\pi}{4}-\frac{\varphi_{\mathrm{c}}}{2}\right)=0,118 \\
\frac{1}{\mathrm{n}_{0}}=0,54 \text { et } a=\frac{A_{c}}{A}=0,1024
\end{gathered}
$$

The decrease in shear stress is expressed by the formula:

$$
\left(\frac{\tau_{h}}{\sigma^{\prime}{ }_{v 0}}\right)_{\text {corrigé }}=\frac{1}{n_{0}}\left(\frac{\sigma_{v 0}}{\sigma_{v 0}^{\prime}}\right)_{\text {initial }}
$$

The assessment of liquefaction risk therefore consists of calculating the cyclic shear stress cyclic shear stress induced by the seismic loading $\tau_{h}$ at each depth and to determine a safety coefficient $\Gamma_{S}$ which is the ratio of the cyclic shear strength noted $\tau_{l}$ to the cyclic shear stress $\tau$, said ratio must be greater than 1,25 . i.e.:

$$
\Gamma_{\mathrm{S}}=\frac{\tau_{1}}{\tau_{\mathrm{h}}} \quad \text { or } \quad \Gamma_{\mathrm{S}}=\frac{\mathrm{C}_{\mathrm{RR}}}{\mathrm{C}_{\mathrm{SR}}}
$$


Table 4. Depth according to the Liquefaction

\begin{tabular}{|c|c|c|c|c|c|c|}
\hline SCP & $\mathbf{Z}$ & CSR & CRR & $\begin{array}{c}\text { CSR } \\
\text { corrected }\end{array}$ & $\begin{array}{c}\Gamma S \\
\text { initial }\end{array}$ & $\begin{array}{c}\Gamma S \text { after } \\
\text { correction }\end{array}$ \\
\hline SCP1 & 8,5 & 0,352 & 0,264 & 0,190 & 0,75 & 1,39 \\
\hline \multirow{4}{*}{ SCP2 } & 13,4 & 0,322 & 0,220 & 0,174 & 0,68 & 1,27 \\
\hline & 15,9 & 0,300 & 0,260 & 0,162 & 0,87 & 1,60 \\
\hline & 16,9 & 0,300 & 0,350 & 0,162 & 1,17 & 2,16 \\
\hline & 20 & 0,280 & 0,220 & 0,151 & 0,79 & 1,46 \\
\hline \multirow{4}{*}{ SCP3 } & 2,2 & 0,390 & 0,460 & 0,211 & 1,18 & 2,18 \\
\hline & 3,5 & 0,380 & 0,420 & 0,205 & 1,11 & 2,05 \\
\hline & 4,2 & 0,370 & 0,220 & 0,200 & 0,59 & 1,10 \\
\hline & 5,2 & 0,370 & 0,220 & 0,200 & 0,59 & 1,10 \\
\hline
\end{tabular}

In addition, it should be noted that after the correction and improvement of the characteristics of bearing capacity and drainage using the technique of ballasted columns shown in Table 4, we note that the safety coefficient goes from a non-admissible value to values exceeding the value of 1.25 , so the risk of liquefaction of the soil is excluded except for the two points located in the depth of 4 to $5 \mathrm{~m}$ and which will be treated within the framework of scouring.

Within the framework of the control of the works of treatment of the grounds by ballasted columns, via 07 drillings with the CPT (Cone Penetration Test)[2] carried out, we will note that starting from the first meter of depth, the values of peak resistance $(\mathrm{Qc})$ in the columns are higher than $10 \mathrm{MPa}$ and reached $68 \mathrm{MPa}$ as maximum value. However, once the depth exceeds $4 \mathrm{~m}$ the peak strength decreases considerably and the local friction follows the trend of the peak strength.

However, the parameter records that attest to a homogeneous compaction of the columns, as well as over their entire height, allow extrapolating the cone penetration resistance values beyond the limits of the tests.

These tests can present difficulties of realization. It is a question of blocking on large elements [12] of the material constituting the column on the one hand, and of deviation of the rod train likely to leave the column on the other hand.

As shown in Figures 8, 9, 10, 11, 12 and 13, the tip of the static penetrometer deviates to look for an easier passage, in the natural ground:

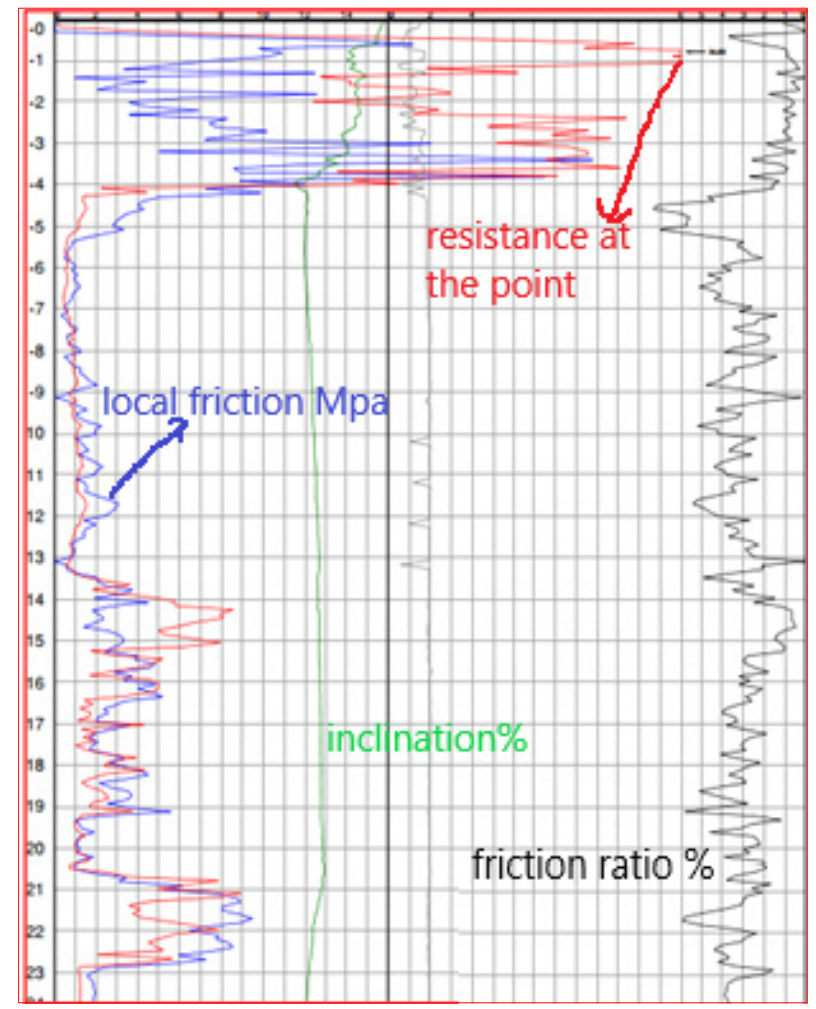

Figure 9. Result CPT CB 104

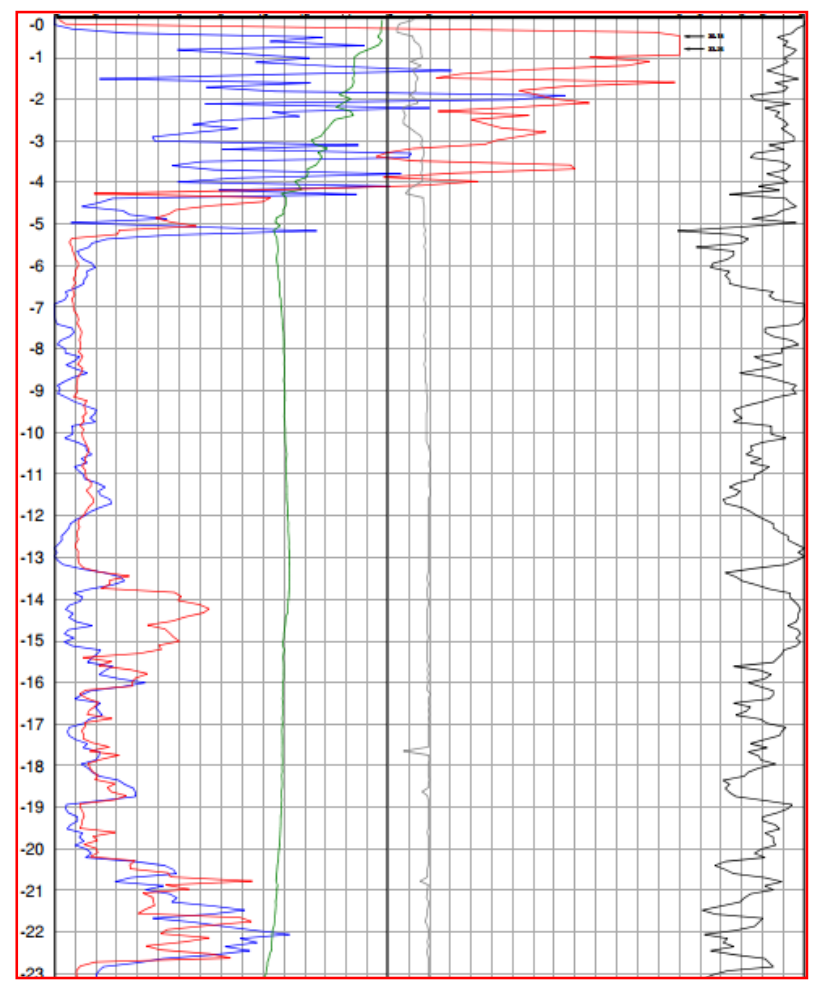

Figure 10. Result CPT CB 174 

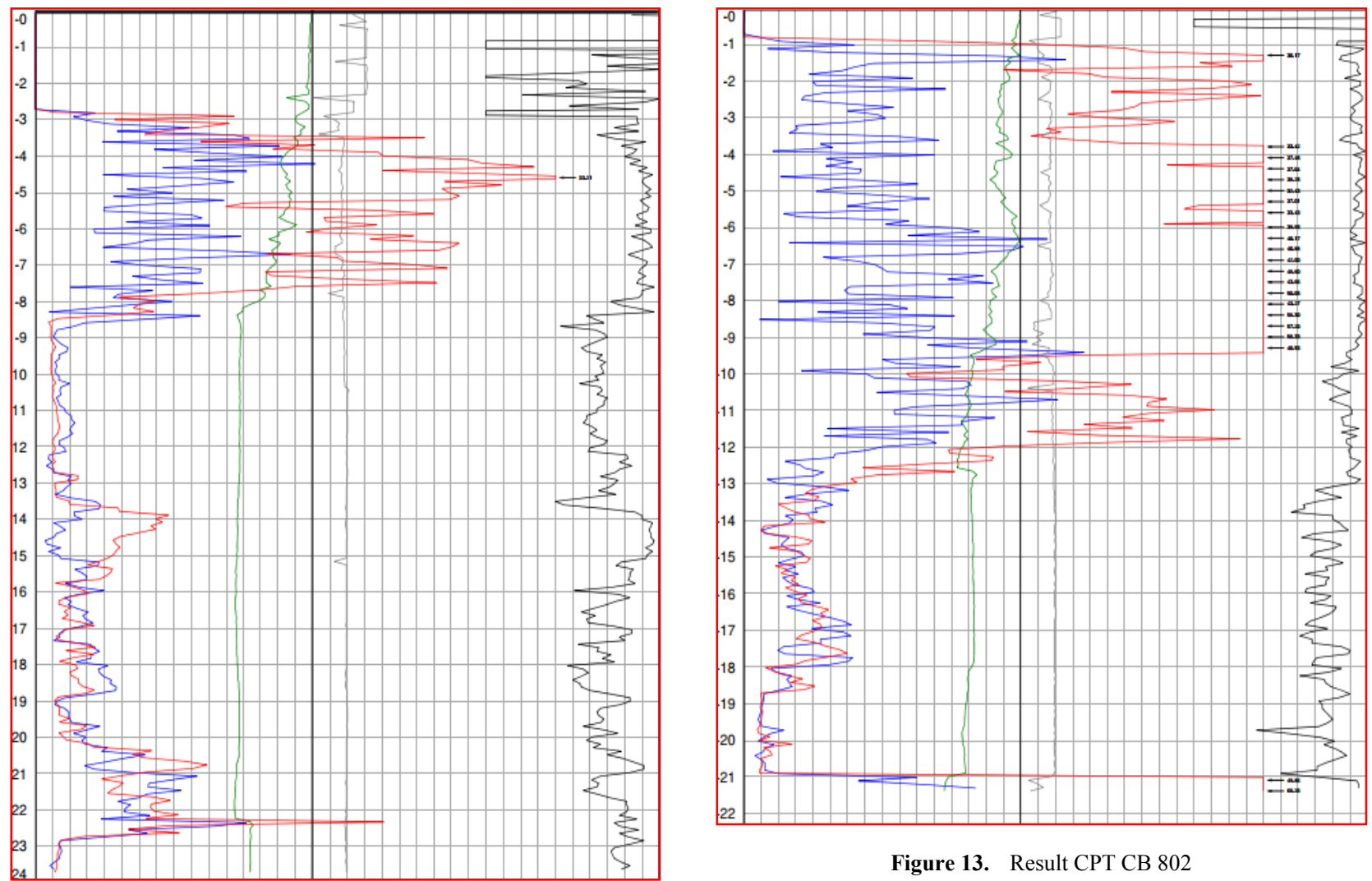

Figure 11. Result CPT CB 123
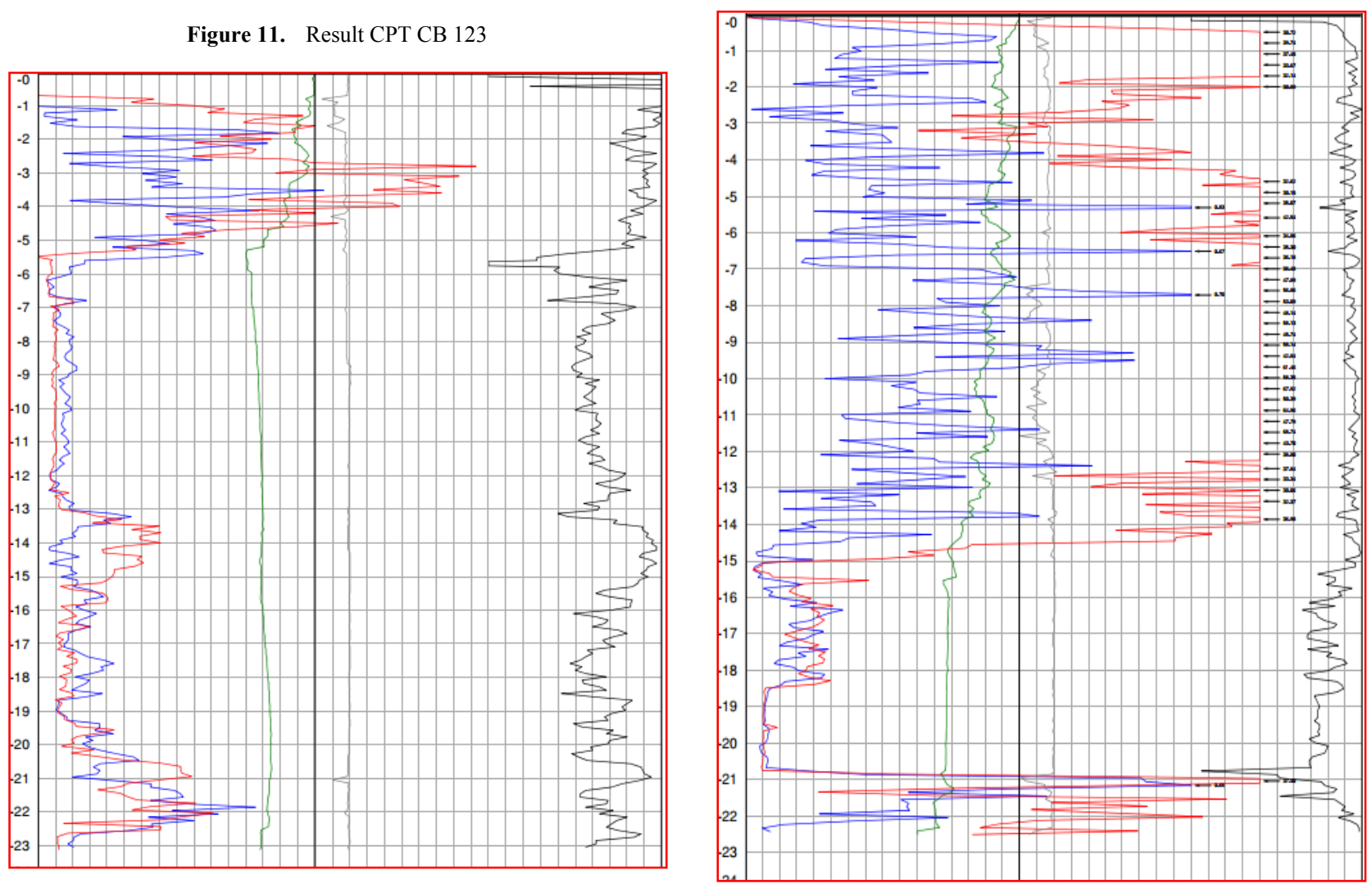

Figure 12. Result CPT CB 217

Figure 14. Result CPT CB 853 


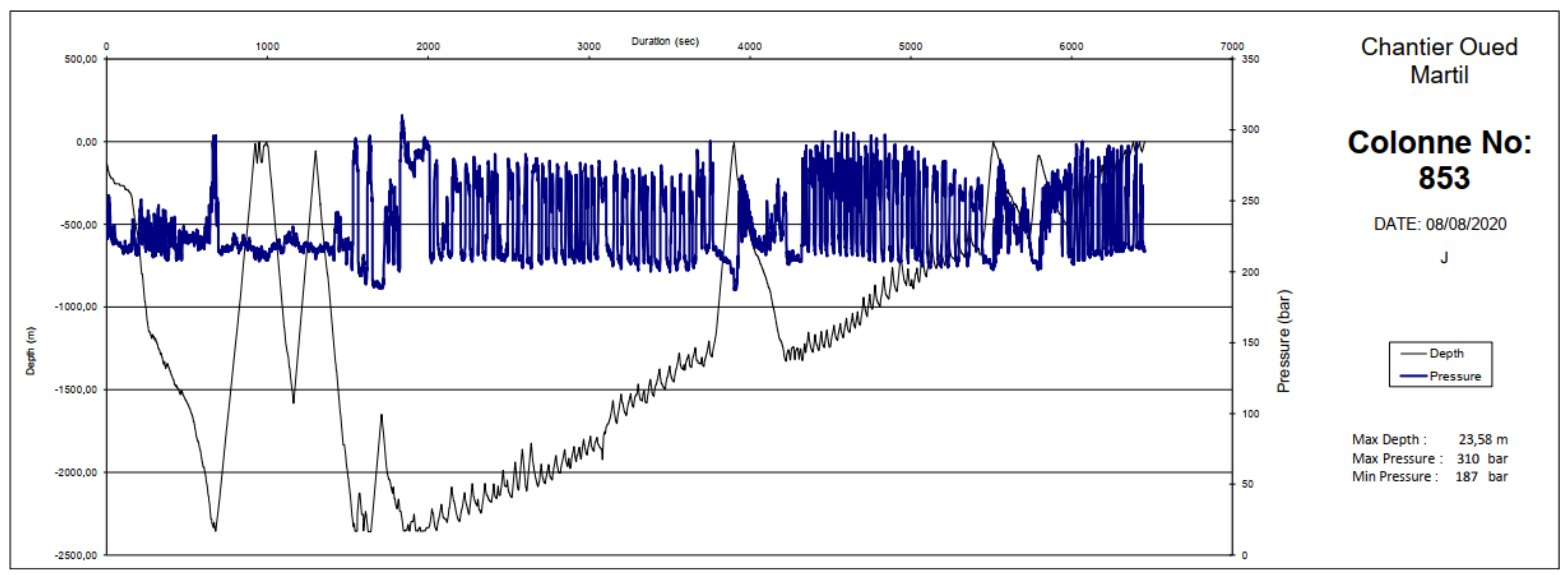

Figure 15. The pressure of the machine as function of depth

It should be noted that the resistance to the tip presented by the red color, the inclination of the column in green color and the friction ration is expressed in blue color.

Analysis of the results in Figure 9 through Figure 14, which show all six 06 CPT control surveys performed, clearly show the following:

- From one meter depth, the peak strength values in the columns are higher than $10 \mathrm{Mpa}$ and reached 68 $\mathrm{MPa}$ as the maximum value,

- Since the columns are very compacted, the tip of the static penetrometer Since the columns are very compacted, the tip of the static penetrometer deviates to look for an easier passage, in the natural ground.

- This can be seen on the CPT diagrams as shown in figure 2. The inclination of the rod represented in green, going in our case, from 5 to $15^{\circ}$.

- Similarly, we can see that the tip resistance drops sharply at a certain depth which varies between $4 \mathrm{~m}$ for figure 9 and $14 \mathrm{~m}$ for figure 14, when the tip resistance decreases the deviation of the rod and friction ratio also increases. This set of elements allows us to affirm that the tip of the rod has left the column to find an easier path in the natural soil.

Also, Figure 15 which presents the recordings of parameters that attest to a homogeneous compaction of the columns, as well as the pressure varies between 200 and 300 bar

In addition, after treatment with stone columns, the soil has improved significantly and the risk of liquefaction becomes negligible:

$$
\begin{array}{ll}
\text { - } & \mathrm{C}_{\mathrm{u}}>15 \mathrm{~m} \\
\text { - } & \mathrm{D}_{50}>1,5 \mathrm{~mm}
\end{array}
$$

The feedback from the use of ballasted columns in seismic zones from the beginning in the 1970's until today shows a very good efficiency of this system, especially against the liquefaction phenomenon. In the studied earthquake cases, ballasted columns have prevented both loss of soil strength under the structure and lateral flow of the surrounding areas, while maintaining their integrity, as opposed to rigid columns whose intrinsic strength must be verified.

More recently, combined systems of pile foundations intercalated with ballasted columns have been implemented to ensure good containment of the pile and to allow it to maintain its bearing capacity in the event of an earthquake. The effectiveness of ballasted columns is explained by their capacity to lighten the soil, by the densification effect of their installation, as well as by the draining role they play.

However, in most of the current cases, only the first two effects are taken into account in the design, and conversely only the drainage effect is taken into account when considering a gravel drain system. In both cases, a calculation taking into account all the favorable effects should allow an optimized design in the future, knowing that their relative importance varies according to the type of soil.

\section{Conclusions}

Finally, the ballasted column plays a role of drain thanks to the strong permeability of the gravel combined with an increase of the hydraulic gradient coming from the phenomenon of dilatation which appears in the ballasted columns at the time of a dynamic solicitation and that the study of the liquefaction developed to become a field of research to whole share

It is to be specified that the two test plans which' were carried out with the two methods of execution of the ballasted columns to know the dry method and the wet method. Beside the executed columns, soundings were carried out in order to define the lithology of the grounds in place.

The columns executed by wet method went down to $22 \mathrm{~m} / \mathrm{TN}$, stopping at the level of the roof of the alluvium of the wadi. The execution did not give rise to surface 
slumps and the incorporated volume of ballast is greater than 1.4 of the theoretical volume.

The columns executed by dry method were stopped at variable depths between 2 to $14 \mathrm{~m} / \mathrm{TN}$, as soon as the vibrator meets a resistant horizon preventing it from continuing its descent. Therefore, with the use of the dry method, the risk of liquefaction will persist since the depth of $22 \mathrm{~m}$ is not reached, despite the fact that the energy source of the hydraulic machine allows to generate a pressure up to 250 bar during the penetration and compaction, nevertheless.

The soil in depth presents hard levels hindering the progress of the vibrator

Therefore, a systematic cross analysis of the SPT and CPT in-situ tests allows diagnosing a risk of liquefaction of the supporting soil. This study should therefore serve as a basis for the analysis of other sites with the same risk conditions.

\section{Outlook and Opportunities}

It can be clearly seen that there are several factors that influence the success of the treatment of liquefiable soils using both dry and wet methods. However, the choice of the treatment method depends on the lithology and the specificity of the site.

Also, the realization of a numerical model according to the geotechnical, geological characteristics taking into account phenomenon of scouring remains like potential variables to be mastered in next studies and researches to determine more this phenomenon of liquefaction of the ground which can generate spectacular disorders.

\section{REFERENCES}

[1] N. Sebbar, A. Lahmili, L. Ouadif, A. Akhssas, et L. Bahi, « Soil treatment in flood areas: case of the road RP4209, in the province of Kenitra (Morocco) », MATEC Web Conf., vol. 149 , p. 02029,2018 , doi: $10.1051 /$ matecconf/2018149 02029 .

[2] P. G. Karagiannopoulos, M. Peronne, et P. Reiffsteck, « ESSAIS PRESSIOMETRIQUES CYCLIQUES AVEC MESURE DE LA PRESSION INTERSTITIELLE LIQUEFACTION DES SOLS », p. 8, 2020.

[3] S. Omar et B. Ramdane, " Analyse du comportement d'ouvrages lourds fondés sur un sol mou renforcé par des colonnes ballastées flottantes », p. 13 .
[4] N. Nehab, K. Baba, L. Ouadif, C. Cherradi, et L. Bahi, « Soft soil strengthening by stone columns: case of the embankment under the bridge "Moulay Youssef" (Rabat/Salé) », MATEC Web Conf., vol. 11, p. 02012, 2014, doi: 10.1051/matecconf/20141102012.

[5] P. Aguado et al., « Recommandations sur la conception, le calcul, l'exécution et le contrôle des colonnes ballastées sous bâtiments et sous ouvrages sensibles au tassement », Rev. Fr. Géotechnique, ${ }^{\circ} 136$, p. $71-86,2011$, doi: $10.1051 /$ geotech/2011136071.

[6] M. Boutahir Born Bencheikh, A. Aidoud, et F. Z. Benamara, " Contribution to the Study of Soil Stabilized by Ballast Columns », Civ. Environ. Eng. Rep., vol. 30, n 3, p. 234252, sept. 2020, doi: 10.2478/ceer-2020-0042.

[7] R. Cudmani et R. Cudmani, " Numerical Study of the Soil-Structure Interaction During Strong Earthquakes », p. 17.

[8] Y. Qi, B. Indraratna, T. Ngo, et F. B. Ferreira, " Advancements in Geo-Inclusions for Ballasted Track: Constitutive Modelling and Numerical Analysis ", Sustainability, vol. 13, $\mathrm{n}^{\circ} 16$, p. 9048, août 2021, doi: $10.3390 /$ su13169048.

[9] K. W. Franke, A. D. Wright, et L. T. Ekstrom, « Comparative Study between Two Performance-Based Liquefaction Triggering Models for the Standard Penetration Test », J. Geotech. Geoenvironmental Eng., vol. 140, $\mathrm{n}^{\mathrm{0}}$ 5, p. 04014010, mai 2014, doi: 10.1061/(ASCE)GT.1943-5606.0001094.

[10] C. Bohn, « Retours d'expérience de l'amélioration de sol par colonnes ballastées en zone sismique », Rev. Fr. Géotechnique, $\mathrm{n}^{0} 144$ - 145, p. 3 - 13, 2013, doi: 10.1051/geotech/2013144003.

[11] M. R. El Ouni, I. Guettaya, et O. Ple, «Évaluation du risque de liquéfaction de la fondation d'un barrage en terre à partir d'essais in situ », Rev. Fr. Géotechnique, n 143, p. 11-24, 2013, doi: 10.1051/geotech/2013143011.

[12] K. W. Franke, A. D. Wright, et L. T. Ekstrom, « Comparative Study between Two Performance-Based Liquefaction Triggering Models for the Standard Penetration Test », J. Geotech. Geoenvironmental Eng., vol. 140, $\mathrm{n}^{\mathrm{o}}$ 5, p. 04014010, mai 2014, doi: 10.1061/(ASCE)GT.1943-5606.0001094.

[13] A. Dhouib et F. Blondeau, Colonnes ballastées: techniques de mise en oeuvre, domaines d'application, comportement, justification, controle, axes de recherche et développement, Presses de l'Ecole Nationale des Ponts et Chaussées. Paris: Presses de l'Ecole Nationale des Ponts et Chaussées, 2005.

[14] K. Adalier et A. Elgamal, « Mitigation of liquefaction and associated ground deformations by stone columns », Eng. Geol., vol. 72, n $3-4$, p. $275-291$, avr. 2004, doi: 10.1016/j.enggeo.2003.11.001 